\title{
Analysis of Selected Internet Platforms of Distributors of Computer Games in the Assessment of Users
}

\author{
Witold Chmielarz \\ University of Warsaw Faculty of Management ul. \\ Szturmowa 3, 02-678 Warszawa, Poland \\ Email: witold@chmielarz.eu
}

\author{
Oskar Szumski \\ University of Warsaw Faculty of Management ul. \\ Szturmowa 3, 02-678 Warszawa, Poland \\ Email: oskar.szumski@uw.edu.pl
}

\begin{abstract}
The aim of this article is to execute a comparative analysis of services and distribution platforms used to purchase computer games. The article is a continuation of research focused on the popularity, use and impact of games on the behavior of a prominent population and analysis of the typical e-shops with games. For the analysis it was chosen the four most common amongst students computer game services and platforms simultaneously found in the first hundreds of searches in Google. CAWI analyzes were used for nine groups of features: transparency, site navigation, quality of information, product search quality, advertising, the quality of the order processing, way of visualization and product promotion from the customer's perspective. Platform analysis was carried out according to: installation package support, application design, search engine quality, transparency, product presentation and security. A qualitative study was conducted to select a sample of selected students using the point method and the point method with preferences to evaluate the distinctive features of the services. A group of over seven hundred randomly selected people from the university was examined. This approach was based on the structure of the article consisting of the presentation of the research hypothesis, the description of the methodology and the research sample, and the analysis of the results and their discussion together with the resulting conclusions. The results of the work may be used by the owners of computer distribution services or platforms and website designers.
\end{abstract}

\section{INTRODUCTION}

$\mathrm{T}$ HE MAIN objective of this study is to analyse the quality of selected Internet platforms of distributors of computer games. This is the fifth of the series of studies carried out among the representatives of academic youth concerning the possibilities of using computer games in education, entertainment, sport, etc. This time the study focuses on the potential distribution platforms providing access to various types of games. The digital distribution of computer games is considered by the authors to be a method of disseminating products consisting in making installation files or a code required to run the application via the Internet available to the player by the publisher. Generally, it is carried out with the application of a platform which is designed especially for this purpose and which provides support in the process of sale and after-sales customer service.

The study considers the data provided by GamesIndustry.biz and a report on the global gaming market in 2017 [1].
According to the published data, the value of the entire gaming market in 2017 amounted to 116 billion dollars, which represents an increase of $10.7 \%$ in relation to 2016. Mobile devices whose share in the total value amounted to $42 \%$ (an increase by $23 \%$ in relation to 2016) were the dominant platform. The income from games running on personal computers and consoles presented a very similar tendency, and it amounted to $27 \%$ and $31 \%$, respectively [1-2]. Thus, it is a market which is developing, and thus it appears to be the research field which deserves further analyses. It is worth noting that the share of the digital platforms used for distribution of computer games in the entire market amounts to around $92 \%$ [3]. In the literature, one may point to the sources which evaluate the influence of the digital gaming platforms on the players [4] or on the natural environment [5], however, there is no comparative assessment of particular platforms from the point of view of users.

The conducted analysis is designed to determine the most important features of websites and platforms distributing computer games as well as motivations of individuals visiting the websites and making purchases.

\section{THE ASSUMPTIONS OF THE RESEARCH METHODOLOGY}

Four platforms were selected for the above-described comparative analysis: GOG (CD Projekt - Poland, (https:// www.gog.com)), Origin - (Electronic Arts Inc.- USA, (https://www.origin.com)), Steam (Valve Corporation USA, (https://store.steampowered.com)) and Uplay (Ubisoft Entertainment - France, (https://store.ubi.com)). The rationale for choosing these platforms was their greatest recognition in Poland and popularity of use (segment leaders) and the diversity with regard to the location of owners. This has been supplemented and verified by an additional analysis of the frequency of the emergence of individual platforms in the first hundred Google search results and the results of the initial part of the survey distributed among students.

The analysis has been divided into four parts: the frequency of the use of games, devices and platforms, payments; comparative analysis of websites of distributors; comparative analysis of installed applications (platforms) and comments.

The analysis of the selected websites was conducted according to a set of thirty-seven indicators, divided into nine 
groups which were verified in previous research [6-7]: website clarity; website support; information quality; the quality of the product search engine; advertising on the site; quality of the ordering process; the method of product distribution; presentation of the product and promotions. The third part of the research was the analysis of final digital distribution applications for PCs with Windows. The applications of the same distributors which were analysed in the first part of the research, namely Valve Corporation (Steam), Electronic Arts Inc. (Origin), Ubisoft Entertainment (Uplay) and CD Projekt (GOG Galaxy), were selected for analysis. The installation of Windows 10 on a virtual machine using VirtualBox 5.0 was used for the analysis. Six groups of parameters were analysed containing in total such criteria as: installation package, the appearance of the application, search engine, transparency, product presentation and security.

Under the circumstances of a dynamic and complex market environment as well as high innovation and competitiveness of solutions, the following questions arise: what characteristics and form should the software of websites and internet platforms adopt to increase their attractiveness to the client? which of the sets of attributes and functionality of these sites seem the most important?

Answers to these questions can be provided by means of a thorough analysis of the requirements of users of online platforms. The quantitative and qualitative research into users' opinions is needed for this purpose, and the study should examine, on the one hand, the use of software and, on the other, the websites which are the sources of its acquisition. Taking into account the fact that there are few and random studies regarding this sphere, both in national literature [8] as well as foreign sources [9-11], the research was based on the authors' own approach consisting of the following steps: selection of the test group, constructing an online survey characterizing websites and distribution platforms from the client's point of view, verification of the survey based on the test group, selection of the most important assessment criteria from the client's point of view, identification of the most important factors influencing the behaviour of the users of websites and distribution platforms and making the revised survey available again on the Internet, along with the dissemination of information about the possibility of its completion, analysis and discussion of the findings, drawing conclusions from research and design recommendations for growing platforms.

The simplified, standardized scoring method of R. Likert [12] was used for the assessment of each specified criterion. On this scale, each criterion was evaluated as follows: 0.00 the criterion is not implemented, 0.25 - the criterion is implemented on a minimal, sufficient level, 0.50 - the criterion is implemented on the medium level, 0.75 - the criterion implementation level is good, 1.00 - full implementation of the criterion.

The selection of online gaming stores was made based on the analysis of the frequency of the first hundred of Google search results, after entering the keywords: witryny dystrybutorów gier (computer games websites) and platformy dys- trybutorów gier (platforms of computer games distributors). This list has been verified by taking into account the opinions of students who frequently and intensely play computer games via digital platforms. The research was carried out in November 2017, on a sample of 713 randomly selected members of the academic community. 549 people completed the survey (over $77 \%$ of respondents), where - after a thorough analysis - 368 survey participants provided complete answers regarding the selected four platforms, which constitutes $67 \%$ of the respondents. $33 \%$ of the sample uses other platforms than the four websites selected for the present analysis.

The online survey was made available on the servers of the Faculty of Management at the University of Warsaw. The sample included the representatives of the academic community, students of all types of studies at two universities: the University of Warsaw and the Vistula Academy of Finance and Business, who were interested in completing the online survey. The study was carried out in two stages. The first stage concerned the evaluation regarding which of the distribution platforms are the most popular among students, which assessment criteria are the most suitable for the evaluation of distributors' websites and which should be applied to evaluate the applications of the selected Internet platforms. In the second stage, the services and selected applications were analysed according to user-defined criteria for the four previously mentioned online platforms. The survey was completed correctly by 368 respondents, evaluating only those websites they were familiar with out of the four websites considered in the study. Some of them rated two ( 55 people) or three websites (26 people). This resulted in a total of 446 observations. GOG was rated by 116 people, Origin by 121 respondents, Uplay by 108 and Steam by 103 individuals. Among the survey participants, there were $72.5 \%$ of women and $27.45 \%$ of men. The average age of respondents was 20.6 years, which was typical for BA and BSc students, mainly with secondary education (over 94\%). Over $42 \%$ of respondents were non-working students, and almost $58 \%$ were working students. Almost $30 \%$ of respondents declared coming from the city of over 100,000 residents, over $26 \%$ from cities with 11-100 thousand inhabitants, and over $43 \%$ from villages or towns up to 10,000 residents.

\section{ANALYSIS AND DISCUSSION OF THE FINDINGS CONCERNING COMPUTER GAME DISTRIBUTORS}

The questionnaire was divided into three parts: an introductory part comprising eight questions, an analytical part (37 questions about websites and 6 questions regarding the application), a field of opinions, comments and recommendations of users, as well as a data sheet describing the test sample.

\section{A. Introductory information}

In order to analyse the obtained data, the scoring method was applied. Each of the respondents assessed individual 
criteria in a subjective way. The assessments were then added together, structured and averaged, followed by a reference to the maximum possible assessment of each indicator, both in the cross-section of websites/applications and the criteria for the respondents evaluating them. From the authors' experience, the findings obtained with the application of comparative analyses of websites by scoring method are just as valuable as those received in the case of more sophisticated methods (AHP/ANP, Electre, Promethee and others) [13].

The first question concerned the moment when people using distribution platforms started playing computer games. Nearly $53 \%$ of respondents said that they started playing computer games in primary school, more than $12 \%$ in preschool age, almost $11 \%$ have been playing games from middle school, high school and college, and $24 \%$ did not play computer games at all. Among the gamers, almost $47 \%$ play games occasionally (once or twice a month), nearly $21 \%$ several times a week, $15 \%$ of the share - several times a month, more than $10 \%$ very rarely - several times a year, and more than $7 \%$ play computer games daily. After specifying this question, it turned out that $59 \%$ of the sample spend less than an hour a week playing computer games, and $16 \%$ play only $1-2$ hours a week. Thirty percent of gamers use only a smartphone for their games, over $23 \%$ a PC or a desktop computer, 19\% use a PC and a notebook, over $20 \%$ use a console or a portable console, and $8 \%$ - a tablet.

The next question concerned PC and console platforms where students have their accounts. Over $25 \%$ have an account on the Origin platform, over $21 \%$ on Steam, almost $10 \%$ on GOG and Uplay, and the remaining $33 \%$ of the share on the Windows Store, Xbox Games Store, Battle.net, PlayStation Store and Nintendo eShop.

Over 53\% describe themselves as experienced players (many years of experience and a wide range of games they played), 9\% believe that they are advanced players (they play almost every day, different games on different equipment at least from elementary school, 15\% claim that they are casual players (novices or people playing only occasionally, e.g. once a month or every three months), and $23 \%$ do not play at all.

The students play mainly games that are free of charge $74 \%$, they do not spend any money on it. Of the remaining $26 \%, 13 \%$ of this share spend up to PLN 20, and only a little over $1 \%$ of the respondents spend over PLN 100.

\section{B. Analysis of the findings concerning websites}

Analyses of the findings concerning the evaluation of websites of the selected computer game distributors were made in two cross-sections: according to the websites and according to the evaluation criteria. The first cross-section was created by averaging the scores obtained for all specified criteria. The assessment for the detailed criterion was calculated as its percentage share in the potential maximum score that could be obtained during the implementation of a given criterion. All websites included in the ranking have achieved ratings exceeding $50 \%$ of the maximum possible score, so it emerges that the clients are generally satisfied with the services they offer. The average assessment in the respondents' opinions is close to $67 \%$. Among the analysed websites, Steam received the highest rating with over $68 \%$, the lowest rating was indicated in the case of GOG Galaxy almost $66 \%$. Thus the spread of results is in the range of $3 \%$, which is very low value with regard to websites. The leading position in the case of Steam was caused by the highest score obtained for such groups of criteria as: product distribution, website clarity, the quality of product search and ordering process quality - where the average rating of these four criteria was $72 \%$. The lowest rating of the GOG Galaxy website resulted from the highest rating in three categories: on-page ads, information quality and website navigation, with an average of these three criteria equal to $63 \%$. Origin, where product presentation received the highest scores and Uplay (the best promotions) have taken the middle positions. The Steam service was the only website which ranked above the average; however, the difference amounted to less than 2 percentage points. The rating of the remaining websites was slightly below average.

Out of all nine groups of criteria, the highest scores were assigned to the product presentation $(76.63 \%)$, the quality of the ordering process $(72.05 \%)$ and the quality of the product search engine $(69.67 \%)$. This demonstrates the pragmatism of website designers, who first of all pay attention to the most important factors from the point of view of sales that may encourage the clients to visit the website again. The lowest scores were recorded in the case of quality of advertising presented on the website $(55.02 \%)$, information quality $(61.51 \%)$ and promotion (64.08\%). This is an interesting phenomenon, which shows that there is a growing dissatisfaction (compared to previous surveys of websites) with the excessive and redundant advertising on the website. The discrepancy between ratings is very large in this case, reaching 23 percentage points. The scores which are above average (which amounts to 66.74\%) were recorded in the case of four groups of criteria - i.e. the above-mentioned factors listed in the three positions, as well as the criterion described as website navigation (67.15\%). More detailed analysis will be present in extended version of the article.

\section{Comparative analysis of platforms}

Analyses of the evaluation results of the installed applications of the selected computer game distributors were also made in two cross-sections: according to websites and according to the evaluation criteria. The first of them was based on the average calculated for each distribution platform based on detailed assessments. The calculation indicates the absolute domination of the Steam application, expressed by the five highest average ratings in five categories of criteria, out of all six possible. In the opinion of respondents, only in the group of the product presentation (i.e. information about products and tools), the GOG Galaxy application gained the advantage of 3 percentage points. At the same time, it is a group of criteria with the highest average 
assessment $(74.02 \%)$. The lowest score $(67.98 \%)$ on all platforms was assigned to the installation package (size and ease of access and ways of its distribution). The difference between the maximum and minimum scores amounts to 6 percentage points. Only the Steam platform with its results is above the average of all results. The lowest score was obtained in the case of the GOG Galaxy platform with the result of $69.93 \%$ by 4 percentage points less than Steam. The scores of Origin and Uplay platforms were only about one percent higher.

The order of the groups of detailed criteria determined the ranking order. The average for Steam was $73.72 \%$. This was mainly due to the high search engine rating (in terms of usability and mode of operation), the appearance of the application, the layout of the elements, scalability to the screen size, clarity and readability (presentation of notifications and messages and the ease of finding information on the menu). The evaluations of Origin (70.95\%) and Uplay (70.55\%) are only slightly lower. The presentation method and the quality of the search engine received high scores, the worst scores were assigned to the installation package in each of the selected applications. Apart from this feature, the scores below the average (amounting to $71.23 \%$ ) were indicated in the case of security - i.e. securing payments and access to purchased products.

For this study, the installation files of applications were downloaded directly from the distributors' websites in the November 2017, bypassing intermediaries. The application designed for the Windows platform was evaluated because all platforms operate on this operating system. Uplay has no alternative to other operating systems, while other platforms also have Mac installations, and Steam also distributes installations on Linux. All installation files were easily accessible from the manufacturer's website.

All platform applications require an active account. Each of them offers the opportunity to work offline, and the ability to add games from outside the platform. The installation process on all platforms proceeded in a similar manner and was not complicated. The most consistent and simplified installation process occurs on the Origin platform. It should also be noted that the installation is usually performed once.

IV. Analysis of the findings With the APplication of A SCORING METHOD WITH PREFERENCES AND THE DISCUSSION OF THE FINDINGS

One of the methods limiting the subjectivity of the experts' evaluations of users in the case of a scoring method (apart from the prior averaging of scores) is the application of unitary preferences, to particular criteria or selected criteria sets. In this study, the authors divided the criteria into three groups which are important or particular categories of users: novice - this category of a user is characterised by the interest in what he or she may evaluate at first sight, as well as the ease of obtaining a product and making a payment; gamer - a person who perceives a game as entertainment, frequently first plays games which are available free of charge on their smartphone, the switches to PC or console games; professional - a person who plays very frequently (every day), is passionate about playing games, plays all the latest games and is ready to pay for using them, plays professionally and can even earn money on the activity, etc. (he or she is mainly interested in the functional aspects: the presentation of the product, the quality of information (the amount of information on a website, the possibility and manner in which one may ask questions, ease of access to information), the quality of the product search engine (the number of modifications, the number of filters, accuracy of answers, clarity of the scores). For each group, the authors adopted one variant with a group of dominating criteria: novice $(70 \%$ for technological aspects, $15 \%$ for the remaining ones); gamer $(70 \%$ for service-related criteria, $15 \%$ for the remaining ones); professional (70\% for functional criteria, $15 \%$ for the remaining ones).

Assigning preferences to particular groups of criteria resulted in slight changes in the rankings. The greatest changes could be observed in the case of the novice category in the case of games where Uplay platform moved from the last place to the second position in the ranking. In the remaining cases, the authors only recorded the reduction of the distance in relation to the previous experiment. Small differences confirm that despite the significant differences with regard to the strategy of the development of the examined platforms, there emerges a specific standardization of the product/services ranges offered to clients. The summary of the positive features of the ranking points to the dominating position of the Steam platform. Only in the variant of an e-gamer, the scores obtained for the Steam and Origin platforms were above the average, and in the case of a gamer only Steam platform reaches the scores beyond average, in the case of the novice, such scores were obtained for Steam and Uplay platforms.

\section{Conclusions and Recommendations}

The conducted survey studies, supplemented with the opinions and comments of clients of computer games shops (the original wording of the respondents' opinions was retained), lead to the following conclusions: the majority of users are satisfied with the appearance and functioning of the websites distributing computer games, which is evidenced (mostly) by high scores (above 50\%) of the specified criteria and their average values, both in the case of the selection of the examined companies as well as the evaluation criteria sets; the respondents emphasise the fact that in the case of the analysed websites they pay particular attention to the website features which allow them to easily obtain information on the content of the game (product information $83 \%$ on average, and the information clarity - over $78 \%$ ), as well as to find out whether they will be able to use all the functionalities of the game (hardware requirements - over $78 \%$ ), ease of registration and payment (registration method and payment options - over $72 \%$ of approval), the lowest scores were obtained in the case of the excessive and intrusive advertising on the website (over $43 \%$ ), despite the fact 
that these are mainly advertisements aimed at self-promotion; Due to the fact that most of the individuals using the platforms consider themselves to be gamers, or even advanced gamers (65\% in total), they are not interested in the manner and possibility to ask questions (51\% and 56\% respectively), as well as restrictions for unregistered users. Majority of the platforms is not designed for novices; clients value the simplicity and clarity of the analysed websites and the scores as well as the ease and intuitiveness of navigation, including the product search, the website selling computer games needs to be easy and clear to use, and a client cannot have any problem finding what he or she needs; the respondents pay attention to an important role of visualisation in attracting customers to computer games shops, simultaneously being aware of the fact that an excessive number of graphic elements may disturb visitors in making a selection and purchase,

At present, Steam is a world leader in the category of computer games distribution, and its high score in this study confirms its position and the awareness of the market where it operates. The lower scores indicated in the case of other platforms may be explained with the fact that it is targeting a rather narrow group of recipients, who do not mind certain shortcomings with regard to the website since they are satisfied with the high quality of the final product they purchase. Origin and GOG have a modern look and very good tools to communicate with the user. The design of the Ubisoft website appears to be obsolete, and thus it may be seen as unattractive. Moreover, another disadvantage of Ubisoft is the lack of consistency with regard to the naming of the website and the application which is installed on a PC to use the purchased games.

One of the limitations of the study was undoubtedly focusing on only four distribution platforms. These are the leading platforms on the market, and in total they constitute - according to statistics - approximately $70-80 \%$ of the market share.

The diversity of the opinions concerning the computer games websites causes some difficulties with regard to generalizing the evaluations. In the case of platforms offering games from independent designers there emerge various phenomena (such as "fake games") [14], which may negatively affect the rating of a particular platform. Despite the high popularity of this type of websites, the similarity of their evaluations to the evaluations of internet shops in other areas of business [15]. Thus, it may be stated that there occurs a specific standardisation of views on how the website should look like. On the other hand, it gives also the idea on the discrepancy between the users' expectations and the projects of their creators. Moreover, one may conclude that the traditional principles of designing websites are still upto-date and applicable.

\section{REFERENCES}

[1] GamesIndustry.biz. (2017) "GamesIndustry.biz presents... The Year In Numbers 2017", https:/www.gamesindustry.biz/articles/2017-12-20gamesindustry-biz-presents-the-year-in-numbers-2017,

[2] SuperData Research. (2018) "Market Brief — 2017 Digital Games \& Interactive Media Year in Review", https://www.superdataresearch.com/market-data/market-brief-year-inreview/

[3] Lifewire. (2017) "Top PC Game Digital Download Services", https:// www.lifewire.com/top-pc-game-digital-download-services-813065

[4] Polygon. (2014) "In the long run, do Steam sales harm gamers?", https://www.polygon.com/2014/1/15/5313142/in-the-long-run-dosteam-sales-harm-gamers

[5] Buonocore, Cathryn E. (2016) "Comparative Life Cycle Impact Assessment of Digital and Physical Distribution of Video Games in the United States", http://nrs.harvard.edu/urn3:HUL.InstRepos:33797406

[6] Chmielarz W., Szumski O.: Analysis of users of computer games, Volume 8, Proceedings of the 2016 Federated Conference on Computer Science and Information Systems, September 11-14, 2016, Gdańsk, Poland eds. M. Ganzha, L. Maciaszek, M. Paprzycki, PTI Warsaw, IEEE New York City, str. 1139-1146, ISSN 2300-5963,

[7] Chmielarz W., Szumski O.: Analysis of Predispositions of E-gamers and Its Relevance in the Use of Computer Games Didactic Process, in: Information Technology in Management, New Ideas and Real Solutions, 11-th Conference of ISM and 14-th Conference of AITM part of FedCSIS, 2016, Editor: E. Ziemba, Book, Lecture Notes in Business Information Processing, Gdańsk, Poland, ISBN 978-3-31953075-8, vol. 277, 2017, pp. 77-102,

[8] Ziemba E. (red.), Towards a Sustainable Information Society. People, Business and Public Administration Perspectives, Cambridge Scholars Publishing, Newcastle upon Tyne, 2016.

[9] Nielsen J., Projektowanie funkcjonalnych serwisów internetowych, Helion, Gliwice, 2003.

[10] Nielsen J., Mobile Website and Application Usability, Nielsen Norman Group Press 2013.

[11] Buonocore, C. E.: Comparative Life Cycle Impact Assessment of Digital and Physical Distribution of Video Games in the United States. Master's thesis, Harvard Extension School, 2016, https://dash.harvard.edu/handle/1/33797406?show=full

[12] Likert R., A Technique for the Measurement of Attitudes, [in:] Archives of Psychology, Nr 140, 1932, str. 1-55.

[13] Chmielarz W., Szumski O., Zborowski M., Kompleksowe metody ewaluacji witryn internetowych, Wydawnictwo Wydziału Zarządzania UW, Warszawa, 2011.

[14] USgamer. (2017) "Valve Removes Nearly 200 "Fake" Games from Steam", https://www.usgamer.net/articles/valve-removes-nearly-200fake-games-from-steam

[15] Chmielarz W., Determinanty rozwoju serwisów dystrybucji treści komercyjnych w Polsce, [in:] Problemy Zarządzania, Wydawnictwo Naukowe Wydziału Zarządzania UW, Problemy wykorzystania systemów informatycznych zarządzania w gospodarce, vol. 13, nr 2 (52), t.1., 2015, str. 51-65, ISSN 1644-9584. 